\title{
Exploring the Social and Emotional Problems of Undergraduates Business Students of Pakistan: A Qualitative Case Study
}

\author{
Najeeb Malik * Ismail Saad ${ }^{\dagger}$
}

\begin{abstract}
Social and emotional health especially of young adults has been a considerable focus of scholarly research in the past few decades all over the world. Much of which is concerned about the number and statistics of people who are suffering from some kind of mental illnesses. This qualitative case study explored the experiences and perceptions of those business university students who are facing some social and emotional challenges and in this important phase of life which have a potential to be converted into something more serious that is, mental disorders. This research identified those variables which are responsible for the social and emotional disturbances of young business university students. In addition, this study also examined those variables which are not specifically related to general culture of a society but to some subcultures which also impact students' social and emotional health. To understand the experiences and perception of those students this study employed focus group interviews, semi-structured open-ended one-on-one interviews, written responses, and projective technique like Rotter Incomplete Sentence Blank (RISB) in the form of self-description, of 15 students at a large private business school in Karachi city. Based on analysis of focus group interviews, RISB, and one-on-one interviews it was found that most of the variables which cause disturbance in students behavior are social, or social psychological, and one's subculture, specific brought up environment, daily hassles and the overall deteriorating conditions of law and order and other factors attributable to institutions play a pivotal role in the development and aggravation of these issues and challenges.
\end{abstract}

Keywords: Social and emotional health; young adults.

\section{Introduction}

It has been observed and substantiated by a considerable body of research all over the world, that students in their university life face multiple problems ranging from psychological to academic and financial to career and social concerns. It is also observed that these problems tend to become so complex with the passage of time that they cannot be easily resolved by students themselves, and in order to solve these issues, they need to seek some professional help (Rickwood, Deane, Wilson, \& Ciarrochi, 2005). In developing countries like Pakistan, India and Bangladesh, the awareness about social and emotional issues is lacking, partly because of their insufficient resources and financial constraints. Other factors are their customs, cultural restrictions and social dynamics.

Social and emotional challenges are generally believed to be issues that grow in the later years of the young adulthood but the roots and causes of these problems are found

\footnotetext{
*PhD Scholar, Iqra University, Pakistan. Email: drnajeeb@iqra.edu.pk
}

${ }^{\dagger}$ Iqra University, Pakistan. 
in children and in the social context (Rosario, Salzinger, Feldman, \& Ng-Mak, 2008). In this study emotional and social challenges refer to those situations and challenges which make young adult (18 to 24 years old) university students academic journey difficult and tend to make their lives miserable. These situations and challenges if given proper attention can easily be tackled and resolved. But if these challenges and issues are not properly addressed and prevented, can pose a serious threat to student's lives, and can also be converted into some serious mental health problems like depression or any other major psychological disorder. Approximately six to eight percent of students suffer or go through emotional issues during the course of their graduate studies (Mead \& MacNeil, 2005), though the exact number of students who suffer from emotional problems cannot be easily established, especially in developing countries. Researches provide sufficient evidence that these students are at greater risk for academic and social challenges in a university environment and later in their practical adult life (Eaton, Davis, Barrios, Brener, \& Noonan, 2007).

Many researchers consider one of the major causes of these issues is the transition from adolescence to adulthood and transition from school education to higher education (Arnett, 2000). During the young adult years (ages 18 to 24 years), many youngsters participate in postsecondary education, and in this phase of life, they are most vulnerable to different mental health issues because of many variables. Mental health problems such as anxiety, depression, and substance abuse are especially common in this age range. It is believed that by understanding the experiences and perceptions of students suffering from social and emotional issues, regarding the obstacles and challenges they face, will lead to the development of successful strategies and appropriate preventive measures.

It has been estimated that worldwide one-third of all adult problems are a result of mental and emotional problems. These problems/issues have a potential to be converted into severe mental disorders like depression, bipolar, and drug and alcohol abuse. Anderson and his associates have found that globally more than one-third of all adults are seriously affected by mental and emotional disorders. But the facilities provided to emotionally disturbed individuals in developed countries especially to university undergraduates are scarce in these countries like Pakistan, India and Bangla Desh (Anderson \& Jane-Llopis, 2006). According to WHO 2001 mental health reports, mental and behavioral disorders are estimated to account for $12 \%$ of the global burden of disease, yet the mental health budgets of the majority of countries constitute less than $1 \%$ of their total health expenditures. More than $40 \%$ of countries have no mental health policy and over $30 \%$ have no mental health programme. Over $90 \%$ of countries have no mental health policy that includes children and adolescents (World Health Organization, 2001).

University undergraduates who suffer from mental and emotional problems in these countries are not provided with any facilities. Further they are stigmatized and labeled in their future lives which doubles their miseries and minimizes their chances of overcoming these problems and challenges successfully. Consequently, life skills necessary to live a healthy emotional and social life are not developed. In that case, education, on the other hand, would not also be able to serve as the propelling force of a culturally assimilating forward-looking society (Saad, 2016). The present study was an attempt to understand the undergraduate's views and the world, their surroundings, their academic life, their 
studies, and their social and emotional lives. It also tried to explore how their relationships get affected by those emotional ups and downs, and whether they see themselves able to utilize necessary life skills in dealing with the problems.

With a focus on understanding and reconstructing the meanings that the participants of this study held about the phenomenon, this investigation was situated in a constructivist philosophical perspective. Constructivism's foundation is built upon the notion that knowledge is constructed through social interpretation rather than discovered (Stake, 1995). This paradigm also recognizes the importance of subjectivity in meaning-making. The humanistic and cognitive theoretical frameworks and Erik Fromm's model of healthy personality also provided the necessary conceptual grounds for the present research.

The purpose of the study was aimed at exploring qualitatively the experiences and perceptions of those under graduate business university students who were facing emotional and social challenges in their academic lives, not attributable to communication or comprehension problems but are the results of social, environmental cultural and emotional factors of their lives.

The overarching purpose of the present study was the exploration of the following questions. These questions broadly cater for the five major personality variables that result in the etiology of social and emotional problems.

The site of the present study Iqra University is based in one of the most socially deprived areas of a very large city. The major reason for selecting this site is that this university is one of the very few universities where the student's population is so heterogeneous. With a student population of more than 15,000 , this prestigious university is very successfully catering the needs of almost all the students belong to different religions and rural and urban areas of the country. This university is fully committed to enabling individual students to achieve their potential in a supportive and inclusive environment. The researcher is also a teacher in this university and teaches courses like psychology and sociology, personal development etc. The university population reflects the ethnic diversity found not just in the locality but also in this very large cosmopolitan city. The university is delivering a wide range of courses to students on five state of the art campuses. It has also been awarded the highest status by the higher education commission (HEC) Pakistan. The most recent report on the university's standing notes some of the following strengths of this university: equality of opportunity and respect for individuals; effective development of students' confidence, self-esteem and critical thinking abilities; extensive range of courses appropriate to the needs of the local community; focus on research and entrepreneurial activities, good faculty, state of the art infrastructure, use of most modern and cutting edge technology, good support for students and strong leadership and management.

Results of this study were expected to provide educators with information, which they could use to provide more effective care to students with social and emotional challenges. 


\section{Survey of Literature}

Although there is a plethora of research regarding the social and emotional issues and challenges of young university students, all over the world and especially in developed countries. However, there is no sufficient data available about the university students with emotional problems in Pakistan (Khan, 1998). Partly it is because there is a little awareness about these issues in Pakistan and other grave social and economic problems do not allow people to think about these issues. Social and emotional problems are conditions that impact a person's thinking, feeling or mood and may affect his or her ability to relate to others and function on a daily basis, (Shelly, 2016). According to world health organization WHO 2017 statistics, Pakistan is a country where mental disorders account for more than $4 \%$ of the total disease burden, with the mental health burden higher among women. It is estimated that 24 million people in Pakistan are in need of psychiatric assistance. In a recent research conducted by Abdullah and Mukhtar, it was found that Pakistan has only 0.19 psychiatrists per 100,000 inhabitants, one of the lowest numbers in WHO Eastern Mediterranean Region and in the whole world (Abdullah et al., 2014).

Zubrick found that psychological problems now affect people at younger ages than it used to be reported earlier (Zubrick et al., 1995). The study by Organization for Economic Co-operation and Development OECD found that variables like student attrition, low academic yield and excessive amounts of time invested in degree studies are common problems in all European Union countries as well (Organisation for Economic Co-operation and Development, 2014). In United Kingdom current figures states that each year 1 in 4 adults will experience at least one diagnosable mental health problem (Counsellingdirectory.org.uk, 2015). Globally, it has been estimated that more than $70 \%$ of people will receive no treatment for their mental and social health issues (Henderson, Evans-Lacko, \& Thornicroft, 2013). In Pakistan, the situation is even worse. Postgraduate students who suffer from emotional problems do not receive any professional help and consequently unable to complete their studies (Khan, 1998). Those students are also believed to have low self-esteem that affects their normal everyday functioning. As far as gender is concerned, in this regard, it is not considered a significant predictor of social and emotional adjustment (Aderi, Jdaitawi, Ishak, \& Jdaitawi, 2013).

Although in some studies female students were found obtaining a higher score for academics than male students (Melendez, 2016). In a recent survey Arnett relates that anxiety disorders are most common among youth and adults who have its impact on youth's ability to properly function in their school or college and family (Arnett, Zukauskienè, \& Sugimura, 2014). Dar in his research on oral communication apprehension with 400 engineering students found that more than $66 \%$ students are suffering from high to average communication anxiety (Dar \& Khan, 2014). In United States of America, suicide is the third leading cause of death among people ages 15-24, and it is the second leading cause of death in college students ages 20-24, moreover teens diagnosed with depression are five times more likely to attempt suicide than adults (Wilkinson, Kelvin, Roberts, Dubicka, \& Goodyer, 2011). Mirza found in a study that in Pakistan general community adult population suffering from emotional problems was 34\% (range $29-66 \%$ for women and $10-33 \%$ for men) (Mirza \& Jenkins, 2004). However, this is believed that the number of student's 
sufferings from emotional problems is increasing day by day (Patrick et al., 2013).

\section{Methodology}

This research was performed using qualitative case study. A case study is seen to be an especially good method for areas where little is previously known (Crescentini \& Mainardi, 2009). Stake (1995) base his approach to case study on a constructivist paradigm. Constructivists claim that truth is relative and it is dependent on one's perspective. This paradigm "recognizes the importance of the subjective human creation of meaning, but doesn't reject outright some notion of objectivity".

The instruments applied to this research were the focus group, one-on-one interviews and application of Rotter Incomplete Sentence Blank RISB. Although Mooney problem checklist could have been applied to this research but keeping in view the nature that is qualitative exploration, the idea of utilizing Mooney problem checklist was dropped and instead RISB a projective technique, was considered more appropriate as corresponding to the need and nature of research. Initially students were screened and selected through a simple self-descriptive questionnaire based on IPAT self-analysis/anxiety form. Then they completed Rotter Incomplete sentences, which is an authentic and widely used projective technique. Then semi-structured in-depth informal interviews and focus group interviews were conducted. The interview schedule was developed and authenticated by a PhD psychologist since the study was about emotional challenges and psychological issues of students. The study sample which was comprised of eight students for in-depth interviews and seven students for focus group discussion, were chosen through purposive sampling. Then the process of coding started. As mentioned by Saldana that the process of coding can be accomplished in two phases, first cycle coding and second cycle coding. In the beginning the researcher engaged himself in first cycle coding or initial coding that is after reading a passage of transcribed interview a phrase was written that captured the essence of participant's perception (Saldaña, 2009). Then an axial coding which involves organizing the data into abstract categories was employed in order to identify and locate themes in participants' responses. The major task of this step was to reassemble data which was separated into component parts during initial coding. During this process of axial coding the researcher also wrote memos which allowed him to attach rich description to the categories.

During the whole process of coding a process of bracketing was utilized, which helped the researcher to put aside his individual experiences and biases (Creswell, 1998) in order to study the perceptions and experiences of participants through their own glasses.

After the completion of the data collection process and data analysis process the researcher had a list of major themes related to how young adults perceive their environment, their life challenges and issues, and how these variables are impacting their lives generally and specifically. 


\section{The Participant's Profile}

The following is a brief depiction of the participants of this study.

Table 1

\begin{tabular}{ccccccc}
\multicolumn{2}{l}{ The participants' profiles } \\
\hline Pseudonyms & $\begin{array}{c}\text { Country and } \\
\text { city/province } \\
\text { of origin }\end{array}$ & $\begin{array}{c}\text { Rural/Urban } \\
\text { Status }\end{array}$ & $\begin{array}{c}\text { Years Spent } \\
\text { in a Karachi } \\
\text { City }\end{array}$ & $\begin{array}{c}\text { Years in a } \\
\text { University }\end{array}$ & $\begin{array}{c}\text { University } \\
\text { Program }\end{array}$ \\
\hline 1 & IR & Pakistan (Karachi) & Rural & By Birth & One & MBA \\
2 & SSD & Pakistan (Karachi) & Rural & By Birth & Two & BBA \\
3 & PR & Pakistan (Interior Sindh) & Urban & Two Years & One & MBA \\
4 & MN & (Pakistan) & Rural & By Birth & Three & BBA \\
5 & SSF & Pakistan (Balochistan) & Urban & One Year & One & BBA \\
6 & RN & Pakistan(KPK) & Urban & By birth & One & MBA \\
7 & SS & Pakistan(Karachi) & Urban & By birth & One & MBA \\
8 & RA & Pakistan (Karachi) & Urban & Four year & One & MBA \\
\hline
\end{tabular}

Table 2

Focus group's Participant's profile

\begin{tabular}{lccc}
\hline Pseudonym & Gender & Age & Program \\
\hline P1 & Female & 20 & BBA \\
P2 & Female & 19 & BBA \\
P3 & Female & 19 & BBA \\
P4 & Female & 24 & MBA \\
P5 & Male & 25 & MBA \\
P6 & Male & 21 & BBA \\
P7 & Male & 24 & MBA \\
\hline
\end{tabular}

\section{Issues for Rural Students living in Urban Environment}

\begin{tabular}{llll} 
Table 3 & & & \\
\hline Individual & Home & University & Community \\
\hline Deficits of social skills & Home sickness & Communication gap between teachers and students & Intercommunity marriages \\
Minority status issues & Socio economic status issues & Poor communication skills & Family quarrels \\
Self-esteem issues & Landlord's issues & Peer status differences & Health care issues \\
Trust issues & Water issues & Low awareness of usage of resources & Domestic violence \\
Acceptance issues & Parents pressures & Pedagogical differences between rural and urban teachers & City law and order situation \\
Traffic issue & Sewerage problems & Problems of cultural assimilation & Financial issues \\
Religious issues & Cooking problems & & \\
& Electricity issues & & \\
\hline
\end{tabular}

\section{Findings and Discussion}

The findings of this study suggested that those identified with emotional and social issues have vague self-perception and they also lack confidence. The participants showed a general dissatisfaction with their lives. Moreover, they also consider that they are living in a rotten society. The researcher also investigated participants' perception about others. The findings suggested that participants had a general mistrust toward other people (mostly non-family members), but they valued the relationship with family members. 
Moreover, whenever they encountered with any problems in their lives, they approached the family members. The findings also suggested that many participants had a feeling of inferiority. The findings of this study found mixed value for money. The participants of this study also expressed that the academic achievement is extremely crucial for their life. Moreover, the participants expressed their feelings of helping others through getting into a social welfare network.

Details of findings have been mentioned below:

The central purpose of the present study was the exploration of the following variables:

1. Emotional Intelligence

2. Achievement

3. Inferiority Feelings

4. Self-Respect

5. Leisure

\section{Main Findings}

In general, these five variables were presented to the heterogeneous group of students, asking them to narrate their present and past experiences, perceptions, obstacles, and challenges.

The first question was about student's social and emotional problems which they face while accomplishing their educational objectives. It was explored that many of their social and emotional problems were related initially to their low self-awareness. In present study most of the participant's appeared as having a very basic sense of their selves which is a main source of their lack of confidence and low emotional intelligence. Generally participants also showed dissatisfaction with life. Participants attributed these problems to society's rotten norms, rituals and law and order situations. Almost all participants' believed that they could come across any life-threatening event at any time and that this is a great source of their anxiety. Corruption in education also appeared as directly affecting participants' lives, as they could not receive the right education and are facing the consequences i.e. lack of confidence and lack of soft and hard skills, language barriers, communication problems and other weak areas of their personality. The transition from high school to higher education was found as one very important variable that caused stress in student's life as this transition has a life-changing nature. Another contributing factor to the social and emotional challenges which this study tried to explore was the factor of trust amongst students, i.e. the extent of their trust on other people, because research is conducive about the relationship between self-esteem and trust building. It was discovered that deep down participants generally don't trust people and this mistrust is also responsible for lowering their self-esteem. 
The second question was about emotional Intelligence which is considered one of the most important variables of healthy personality. Daniel Goleman's research is continuously proving that emotional intelligence helps people in countless ways, and without emotional intelligence success and survival is difficult in today's competitive world (Goleman, 2001). Lack of emotional intelligence and other soft and people's skills appeared as very significant cause of student's social and emotional challenges. As mentioned by Robles (2012) that without developing certain people and soft skills it is almost impossible to lead a successful life as an individual and as an executive. The lack of soft skills was found as one very important variable related to participants social and emotional issues as it was affecting almost all areas of their lives.

The third question was about their inferiority complex. Generally participants of the study seemed confused and unaware about their feelings of inferiority and also about feelings of superiority. Their confusion also seemed to affect their assertive behavior as they said that they can stand up for their rights but further probing revealed that this is not right and they usually face problems in protecting their rights.

The fourth question was about maintaining self-respect. Achievement and right and moral sense of achievement appeared as the answer of maintaining participant's selfrespect. Though all participants wanted to achieve something big in life but through reasonable means and with their efforts. Surprisingly in present study money was considered necessary by all participants but not to the extent that they would give up their values and morality for money; this also portrayed the mature side of students' personality. Philanthropy also appeared as an agent of enhancing student's self-respect and dignity.

Leisure activities also give a strong clue to one's balanced state of mind. Caldwell (2005) found that leisure and involvement in leisure activities could be therapeutic and good for mental health. The present study revealed that almost all the participants especially girls, because of societal constraints, spend most of their free time on social media and becoming more and more dependent on social media which is disturbing the balance of their lives. Apart from spending time on social media many male participants stated that they are also doing something positive for their society and are involved in many philanthropic activities.

The data of the study revealed that almost all the issues and challenges cause disturbance in students who are facing one or more social or cultural issues, resulting in poor performance in their academic life and the life afterward.

In interpreting the findings of this study, it is important to acknowledge its limitations. The sample size was small and derived from only one university.The result of student's views toward social and emotional experiences showed that they were not satisfied generally with their academic progress. Different themes clearly identified that the initial academic experience was very stressful for many business students. Students in the second year experienced more anxiety compared with third and fourth year students. Initial university experience was the most anxiety producing part of student university experience. In this study fear of communication (especially in English as English is an official academic language and many participants were not much familiar with this language because of their backgrounds and prevailing deteriorating situation of education in 
country), lack of confidence, fear of failure, experience of living without family, deteriorated law and order situation, and corruption were expressed by the students as anxietyproducing situations in their initial university experiences. Emotional Intelligence was one of the main themes in this study and it was found that many students are blessed with this ability, but at the same time many students showed that they have a very vague self-concept and generally they are not satisfied with life. It was also found that many students have ability to empathize with other people. Though this positive ability and very important component of emotional intelligence has also adverse effects on student's emotional health as they observe many people suffering and facing problems in society. Many students were found with moderate level of achievement with a commitment of serving their nation and eradicating the prevalent current corrupt state of affairs.

\section{Implications and Recommendations}

The findings of the current study are significant in Pakistani context where masses generally and students specially are facing extreme social and emotional challenges for their day to day and academic survival. First of all, the state must realize that without effective and strong development of all major institutions of society, it would not be possible to cater the needs of learners effectively, especially those who are facing psychological issues due to social challenges. Moreover, teachers should be trained in-line with the humanistic and constructivist approaches in order to bring a fruitful change in their students' lives. Awareness amongst all the segments of society also needs to be developed about the ways in which mental health and emotional well-being affect student's lives, goal attainment, and achievement. Liberal arts courses should also be incorporated pertaining to language skills, self-development, philosophy, psychology, literature and leadership as they enhance learner's growth and overall personality development. Spiritual well-being is one of the core human components that reduce suffering, increase coping and promote mental health; higher education institutions should also consider and pay attention to this important variable (Papazisis, Nicolaou, Tsiga, Christoforou, \& Sapountzi-Krepia, 2014). University staff and faculty should be enabled to address mental health issues through good leadership (at senior and middle-management levels) and they should be provided adequate resources like counseling centers. And most importantly as stated by many research participants, that the ministries of education and social policy makers should give top priority to pursue corruption as an obstacle to high-quality education and to national development, starting with a declaration of a zero-tolerance approach to corruption as an essential element in strengthening the quality of education and student's wellbeing. 


\section{References}

Abdullah, M. A., Mukhtar, F., Wazir, S., Gilani, I., Gorar, Z., \& Shaikh, B. T. (2014). The health workforce crisis in Pakistan: A critical review and the way forward. World Health Popul, 15(3), 4-12.

Aderi, M., Jdaitawi, M., Ishak, N. A., \& Jdaitawi, F. (2013). The influence of demographic variables on university students' adjustment in North Jordan. International Education Studies, 6(2), 172-178.

Anderson, P., \& Jane-Llopis, E. (2006). Mental health promotion and mental disorder prevention across European member states: A collection of country stories. European Communities, Luxembourg.

Arnett, J. J. (2000). Emerging adulthood: A theory of development from the late teens through the twenties. American Psychologist, 55(5), 469-480.

Arnett, J. J., Žukauskienè, R., \& Sugimura, K. (2014). The new life stage of emerging adulthood at ages 18-29 years: implications for mental health. The Lancet Psychiatry, 1(7), 569-576.

Caldwell, L. L. (2005). Leisure and health: why is leisure therapeutic? British Journal of Guidance E Counselling, 33(1), 7-26.

Crescentini, A., \& Mainardi, G. (2009). Qualitative research articles: Guidelines, suggestions and needs. Journal of Workplace Learning, 21(5), 431-439.

Creswell, J. W. (1998). Qualitative inquiry and research design: Choosing among five tradition. Thousand Oaks, CA: Sage.

Dar, M. F., \& Khan, I. (2014). Oral communication apprehension among undergraduate engineering students in Pakistan. Journal of Education $\mathcal{E}$ Social Sciences, 2(2), 144-153.

Eaton, D. K., Davis, K. S., Barrios, L., Brener, N. D., \& Noonan, R. K. (2007). Associations of dating violence victimization with lifetime participation, co-occurrence, and early initiation of risk behaviors among US high school students. Journal of Interpersonal Violence, 22(5), 585-602.

Goleman, D. (2001). An ei-based theory of performance. The emotionally intelligent workplace: How to select for, measure, and improve emotional intelligence in individuals, groups, and organizations, 1, 27-44.

Henderson, C., Evans-Lacko, S., \& Thornicroft, G. (2013). Mental illness stigma, help seeking, and public health programs. American Journal of Public Health, 103(5), 777780.

Khan, W. (1998). Evaluation of guidance and counselling programmes in the teacher training institutions of Pakistan (Unpublished doctoral dissertation). University Of Peshawar.

Mead, S., \& MacNeil, C. (2005). Peer support: A systemic approach. Family Therapy Magazine.

Melendez, M. C. (2016). Adjustment to college in an urban commuter setting: The impact of gender, race/ethnicity, and athletic participation. Journal of College Student Retention: Research, Theory \& Practice, 18(1), 31-48.

Mirza, I., \& Jenkins, R. (2004). Risk factors, prevalence, and treatment of anxiety and depressive disorders in Pakistan: Systematic review. Bmj, 328(7443), 794. 
Organisation for Economic Co-operation and Development . (2014). Education at a glance: Oecd indicators.

Papazisis, G., Nicolaou, P., Tsiga, E., Christoforou, T., \& Sapountzi-Krepia, D. (2014). Religious and spiritual beliefs, self-esteem, anxiety, and depression among nursing students. Nursing $\mathcal{E}$ Health Sciences, 16(2), 232-238.

Patrick, C. J., Venables, N. C., Yancey, J. R., Hicks, B. M., Nelson, L. D., \& Kramer, M. D. (2013). A construct-network approach to bridging diagnostic and physiological domains: Application to assessment of externalizing psychopathology. Journal of Abnormal Psychology, 122(3), 902.

Rickwood, D., Deane, F. P., Wilson, C. J., \& Ciarrochi, J. (2005). Young peoples helpseeking for mental health problems. Australian e- Journal for the Advancement of Mental Health, 4(3), 218-251.

Robles, M. M. (2012). Executive perceptions of the top 10 soft skills needed in today's workplace. Business Communication Quarterly, 75(4), 453-465.

Rosario, M., Salzinger, S., Feldman, R. S., \& Ng-Mak, D. S. (2008). Intervening processes between youths exposure to community violence and internalizing symptoms over time: The roles of social support and coping. American Journal of Community Psychology, 41(1-2), 43-62.

Saad, I. (2016). Education in Pakistan. Pakistan prospects and perspectives. Journal of Education E Social Sciences, 4(1), 30-50.

Saldaña, J. (2009). An introduction to codes and coding. The coding manual for qualitative researchers.

Shelly, C. (2016). Students' attitudes to mental health; measuring stigma and help seeking behaviour.

Stake, R. E. (1995). The art of case study research. Sage.

Wilkinson, P., Kelvin, R., Roberts, C., Dubicka, B., \& Goodyer, I. (2011). Clinical and psychosocial predictors of suicide attempts and nonsuicidal self-injury in the adolescent depression antidepressants and psychotherapy trial (ADAPT). American Journal of Psychiatry, 168(5), 495-501.

World Health Organization. (2001). The world health report 2001: Mental health: New understanding, new hope.

Zubrick, S. R., Silburn, S. R., Garton, A. F., Burton, P., Dalby, R., Carlton, J., \& Lawrence, D. (1995). Western Australian child health survey: Developing health and well-being in the nineties. 